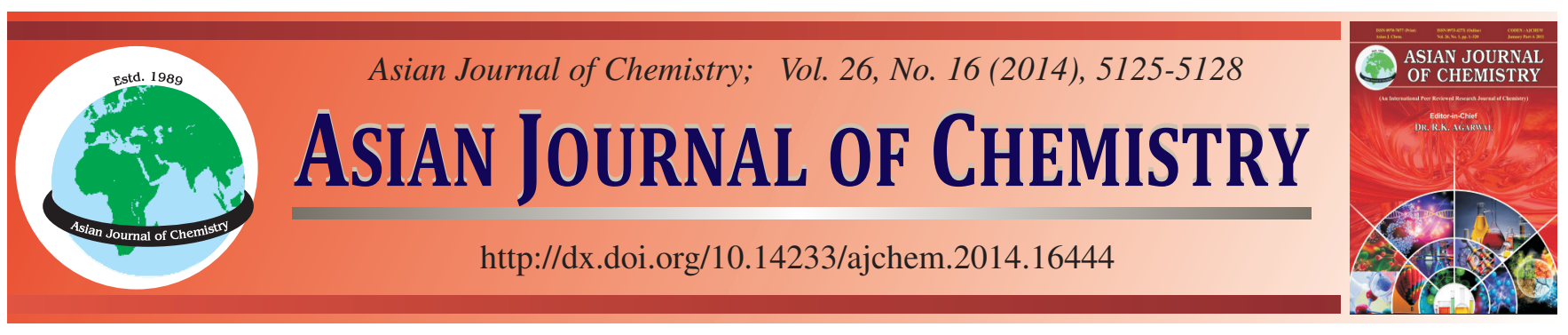

\title{
Kinetics and Mechanism of Ru(III) Catalyzed Periodate Oxidation of Methyl Glycol and Diacetone Alcohol in Perchloric Acid
}

\author{
KAMINI SINGH and R.A. SINGH*
}

Chemical Kinetics Research Laboratory, Department of Chemistry, Tilak Dhari P.G. College, Jaunpur-222 002, India

*Corresponding author: E-mail: rasinghtdc@ rediffmail.com

\begin{abstract}
Kinetics of oxidation of methyl glycol (MG) and diacetone alcohol (DAA) by periodate in the presence of ruthenium(III) chloride as homogeneous catalyst have been studied in acidic medium. The results indicate zero order dependence of the reaction on $\left[\mathrm{IO}_{4}{ }^{-}\right]$while first order kinetics with respect to $[\mathrm{Ru}(\mathrm{III})]$ was observed. First order in both [MG] and [DAA] was observed while positive effect of [H $\left.\mathrm{H}^{+}\right]$was exhibited. Variation of ionic strength of the medium and addition of potassium chloride did not bring about any significant change in the rate of the reaction. Showing thus zero effect of ionic strength and added chloride ions. A suitable mechanism consistent with kinetic results has been proposed and rate law has been deduced for the title reactions.
\end{abstract}

Keywords: Kinetics, Mechanism, Methyl glycol, Diacetone alcohol, Periodate.

\section{INTRODUCTION}

In recent years, the use of transition metals ions, such as osmium, iridium, palladium and ruthenium either alone or as binary mixtures as catalysts in the oxidation of several redox processes is of considerable interest of these reactions. Ruthenium(III) chloride utility as nontoxic and homogeneous catalyst has been known ${ }^{1-7}$, but less attention has been paid to explore the catalytic role of $\mathrm{Ru}(\mathrm{III})$ with periodate $\mathrm{e}^{7-10}$ as an oxidant. Earlier, oxidation kinetics ${ }^{11}$ of methyl glycol and diacetone alcohol by osmium tetroxide in alkaline medium have been reported. In view of less work on the periodate oxidation with industrically important substrates, there seems to be much exciting chemistry in further probing the oxidative capacity of periodate in the oxidation of methyl glycol and diacetone alcohol particularly in the presence of $\mathrm{Ru}(\mathrm{III})$ in perchloric acid medium. In present communication, a detailed kinetic studies based mechanistic steps in $\mathrm{Ru}(\mathrm{III})$ catalyzed periodate oxidation of methyl glycol (MG) and diacetone alcohol (DAA) have been reported.

\section{EXPERIMENTAL}

Standard solutions of methyl glycol and diacetone alcohol (both of E. Merck) were prepared by directly weighing their samples and dissolving them in doubly distilled water. $1 \mathrm{~g}$ sample of ruthenium(III) chloride (Johnson \& Matthey) was prepared in $100 \mathrm{~mL}$ of $0.01 \mathrm{~mol} \mathrm{dm}^{-3} \mathrm{HCl}$ solution and there after it was diluted to $1 \mathrm{~L}$ in which its final strength was noted. Sodium metaperiodate (Koch-Light) was used after recrysta- llization and its stock solution, prepared in doubly distilled water was standardized iodometrically. All other chemicals used were of AR grade. Perchloric acid (70 \% of E. Merck) was used as source of $\mathrm{H}^{+}$ions and sodium perchlorate (E. Merck) was used to vary the ionic strength of the medium.

Kinetic measuremental: A thermostatic water bath was used to maintain the desired temperature within $\pm 0.1^{\circ} \mathrm{C}$. The appropriate volumes of methyl glycol or diacetone alcohol, $\mathrm{HClO}_{4}, \mathrm{Ru}(\mathrm{III})$ chloride and required volume of water were taken in a black coated reaction vessel which was thermostated at $303 \mathrm{~K}$ for thermal equilibrium. After about $0.5 \mathrm{~h}$ when the reaction mixture had attained the temperature of the experiment, the requisite volume of periodate solution, also thermostated at the same temperature, was added rapidly into the reaction vessel to make the total volume of the reaction mixture $100 \mathrm{~mL}$. Immediately $5 \mathrm{~mL}$ aliquot of reaction mixture was taken out and poured into acidified potassium iodide solution.

The iodine liberated in equivalent amount was estimated with standard solutions of sodium thiosulphate and the titre volume at zero time was noted. Similar reading were recorded at different intervals of time by estimating $5 \mathrm{~mL}$ of reaction mixture iodometrically and thus progress of the reaction was monitored periodate. Each kinetic run was studied for two half life of the reaction. The rate of the reaction $(-\mathrm{dc} / \mathrm{dt})$ was determined by the slope of the tangent drawn at a fixed $\left[\mathrm{IO}_{4}^{-}\right]$in each kinetic run. The order of the reaction in each kinetic run was calculated by $\log -\log$ plot of $(-\mathrm{dc} / \mathrm{dt})$ versus concentration of reactants. 
Stoichiometry and product analysis: Different sets of reaction mixture under the conditions $\left[\mathrm{IO}_{4}^{-}\right]>$[Substrate] were equilibrated at $303 \mathrm{~K}$ for $72 \mathrm{~h}$. Estimation of unconsumed $\mathrm{IO}_{4}{ }^{-}$in each set revealed that 2 and 4 moles of periodate were consumed in oxidation of each mole of methyl glycol and diacetone alcohol, respectively. Accordingly following stoichiometric equations can be formulated as (1) and (2).

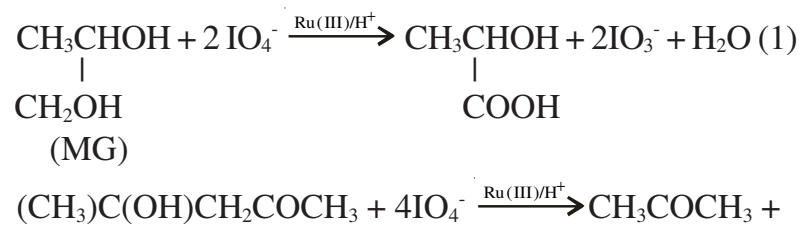

(DAA) $\quad \mathrm{CH}_{3} \mathrm{COOH}+\mathrm{CO}_{2}+4 \mathrm{IO}_{3}^{-}+\mathrm{H}_{2} \mathrm{O}$ (2)

The corresponding oxidation products of $\mathrm{MG}$ and DAA were identified by spot tests ${ }^{12}$. The presence of acetone in equation (2) was also confirmed by its 2,4-dinitrophenyl hydrazone derivative.

\section{RESULTS AND DISCUSSION}

The kinetics of oxidation of methyl glycol (MG) and diacetone alcohol (DAA) by periodic in the presence of little $[\mathrm{Ru}(\mathrm{III})]$ in aqueous acidic solution were investigated at several initial concentrations of all the reactants at $303 \mathrm{~K}$. The value of initial rate $(-\mathrm{dc} / \mathrm{dt})$ in each kinetic run was calculated from the slope of the tangent of the straight line obtained on plotting unconsumed $\left[\mathrm{IO}_{4}{ }^{-}\right]$versus time at, fixed $\left[\mathrm{IO}_{4}{ }^{-}\right]$except in $\left[\mathrm{IO}_{4}^{-}\right]$ variation when tangent has been drawn at a fixed time. The initial rate $(-\mathrm{dc} / \mathrm{dt})$ thus obtained was used to determine the order of reaction with respect to each reactant.

On varying $\left[\mathrm{IO}_{4}^{-}\right]$rate of reaction $(-\mathrm{dc} / \mathrm{dt})$ remains practically constant in oxidation of each of MG and DAA, showing thus zero-order kinetics in [periodate] (Table-1). At fixed concentrations of all other reagents, increase in $[\mathrm{MG}]$ and [DAA] increased the value of (-dc/dt) linearly, showing firstorder in both [MG] and [DAA]. This was further confirmed by slopes $\left(\mathrm{k}_{1}\right)$ of straight lines (Fig. 1) obtained on plotting $(-\mathrm{dc} / \mathrm{dt})$ versus $[\mathrm{MG}]$ or $[\mathrm{DAA}]$, in agreement with experimental $\mathrm{k}_{1}$ values (where $\mathrm{k}_{1}=(-\mathrm{dc} / \mathrm{dt}) /[$ Substrate] $)$. The value of $(-\mathrm{dc} / \mathrm{dt})$ also increased linearly with increase in $[\mathrm{Ru}(\mathrm{III})]$ in oxidation of both GM and DAA, indicating thus first-order in $[\mathrm{Ru}(\mathrm{III})]$. The graphical $\mathrm{k}_{1}$ values (obtained from the slope of the plot between $(-\mathrm{dc} / \mathrm{dt})$ and $[\mathrm{Ru}(\mathrm{III})]$ were found in close agreement with corresponding experimentally observed $\mathrm{k}_{1}$ value (Table-1), showing and confirming first-order in $[\mathrm{Ru}(\mathrm{III})]$ in oxidation of both MG and DAA (Fig. not shown here).

Table- 2 contains the results of variation of $\left[\mathrm{H}^{+}\right]$and temperature as well as effect due to addition of $\mathrm{KCl}$. Increase in $\left[\mathrm{H}^{+}\right]$ increased the rate non-linearly, showing positive effect of $\left[\mathrm{H}^{+}\right]$ on the rate of oxidation of both MG and DAA. Addition of $\mathrm{KCl}$ to the reaction mixture was found to have no significant effect, indicating zero effect of $\left[\mathrm{Cl}^{-}\right]$on rate oxidations. Variation of ionic strength from $1.20 \times 10^{-2} \mathrm{M}$ to $6 \times 10^{-2} \mathrm{M}$ (in case of $\mathrm{MG}$ ) and from $2.33 \times 10^{-2} \mathrm{M}$ to $7.33 \times 10^{-2} \mathrm{M}$ (in case of DAA) did not bring about significant change in oxidation of their rates, showing negligible effect of ionic strength on rate of

\begin{tabular}{|c|c|c|c|c|c|c|}
\hline \multicolumn{7}{|c|}{$\begin{array}{r}\text { TABLE-1 } \\
\text { EFFECT OF VARIATION OF [REACTANTS }] \\
{\left[\mathrm{HClO}_{4}\right]=1.00 \times 10^{-2} \mathrm{~mol} \mathrm{dm}^{-3}[\mathrm{MG}] \text { AND } 2 \times 10^{-2} \mathrm{mo}}\end{array}$} \\
\hline \multirow{2}{*}{$\begin{array}{l}{\left[\mathrm{NaIO}_{4}\right] \times 10^{3}} \\
\left(\mathrm{~mol} \mathrm{dm}^{-3}\right)\end{array}$} & \multirow{2}{*}{$\begin{array}{l}\text { [Substrate] } \times 10^{2} \\
\left.(\mathrm{~mol} \mathrm{dm})^{-3}\right)\end{array}$} & \multirow{2}{*}{$\begin{array}{l}{[\mathrm{Ru}(\mathrm{III})] \times 10^{6}} \\
\left.(\mathrm{~mol} \mathrm{dm})^{-3}\right)\end{array}$} & \multicolumn{2}{|c|}{$[-\mathrm{dc} / \mathrm{dt}] \times 10^{7}\left(\mathrm{~mol} \mathrm{dm}^{-3} \mathrm{~s}^{-1}\right)$} & \multicolumn{2}{|c|}{$\mathrm{k}_{1}^{\mathrm{a}} \times 10^{6}\left(\mathrm{~s}^{-1}\right)$} \\
\hline & & & MG & DAA & MG & DAA \\
\hline 0.80 & 2.00 & 9.60 & 0.65 & 1.72 & - & - \\
\hline 1.00 & 2.00 & 9.60 & 0.64 & 1.68 & - & - \\
\hline 1.25 & 2.00 & 9.60 & 0.67 & 1.70 & - & - \\
\hline 1.67 & 2.00 & 9.60 & 0.63 & 1.74 & - & - \\
\hline 2.50 & 2.00 & 9.60 & 0.68 & 1.64 & - & - \\
\hline 4.00 & 2.00 & 9.60 & 0.64 & 1.72 & - & - \\
\hline 1.00 & 0.50 & 9.60 & 0.17 & 0.42 & 3.40 & 8.40 \\
\hline 1.00 & 1.00 & 9.60 & 0.33 & 0.86 & 3.30 & 8.60 \\
\hline 1.00 & 1.50 & 9.60 & 0.49 & 1.29 & 3.26 & 8.60 \\
\hline 1.00 & 2.00 & 9.60 & 0.66 & 1.74 & 3.30 & 8.70 \\
\hline 1.00 & 2.50 & 9.60 & 0.84 & 2.12 & 3.36 & 8.48 \\
\hline 1.00 & 3.00 & 9.60 & 1.02 & 2.60 & 3.40 & 8.66 \\
\hline 1.00 & 2.00 & $1.20^{\mathrm{b}}$ & - & 0.22 & - & $18.33^{\circ}$ \\
\hline 1.00 & 2.00 & $1.60^{\mathrm{b}}$ & 0.11 & - & 6.87 & - \\
\hline 1.00 & 2.00 & $1.80^{\mathrm{b}}$ & - & 0.32 & - & $17.78^{\circ}$ \\
\hline 1.00 & 2.00 & $2.40^{\mathrm{b}}$ & - & 0.44 & - & $18.33^{\circ}$ \\
\hline 1.00 & 2.00 & $3.20^{\mathrm{b}}$ & 0.21 & - & 6.56 & - \\
\hline 1.00 & 2.00 & $3.60^{\mathrm{b}}$ & - & 0.63 & - & $17.50^{\circ}$ \\
\hline 1.00 & 2.00 & $4.80^{\mathrm{b}}$ & 0.31 & 0.85 & 6.46 & $17.71^{\circ}$ \\
\hline 1.00 & 2.00 & $6.00^{\mathrm{b}}$ & - & 1.08 & - & $18.00^{\circ}$ \\
\hline 1.00 & 2.00 & $6.40^{\mathrm{b}}$ & 0.42 & - & 6.40 & - \\
\hline 1.00 & 2.00 & $8.00^{\mathrm{b}}$ & 0.53 & - & 6.62 & - \\
\hline 1.00 & 2.00 & $9.60^{\mathrm{b}}$ & 0.64 & - & 6.67 & - \\
\hline $\mathrm{k}_{1} \times 10^{6}=\frac{(}{[S}$ & $\frac{1}{t e]}=k$ & $10^{3}=\frac{(-\mathrm{dc} /}{[\mathrm{Ru}(\mathrm{I})}$ & $0^{3} \mathrm{~s}^{-1}$ & $4=\frac{(}{[1}$ & $\times 10^{-2}$ & \\
\hline
\end{tabular}


oxidation. Rate measurements at 298, 303, 308 and $313 \mathrm{~K}$ in oxidation of MG and DAA led to calculate energy of activation $\left(E_{a}\right)$, entropy of activation $\left(D S^{\#}\right)$, free energy of activation $\left(\Delta G^{\#}\right)$ whose values are given in Table-3.

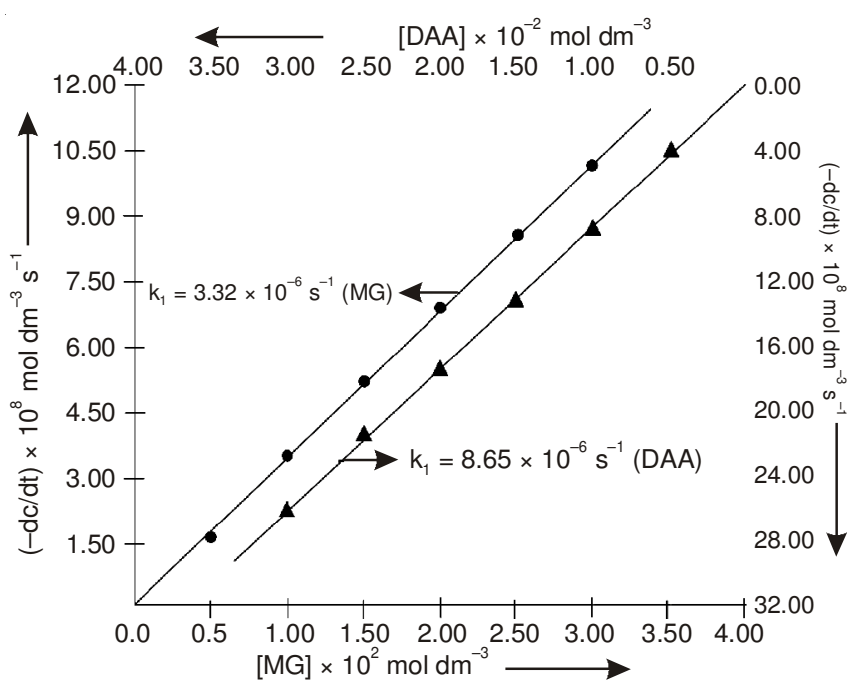

Fig. 1. Plot of (-dc/dt) vs. [MG] or [DAA] under the condition of Table-1

In aqueous solution ( $\mathrm{pH}=0$ to 7 ) of acid periodic acid exists as equilibrium between free acid $\left(\mathrm{H}_{5} \mathrm{IO}_{6}\right)$ and its various ions.

$$
\begin{aligned}
& \mathrm{H}_{5} \mathrm{IO}_{6} \rightleftharpoons \mathrm{H}_{4} \mathrm{IO}_{6}^{-}+\mathrm{H}^{+} \\
& \mathrm{H}_{4} \mathrm{IO}_{6}^{-} \rightleftharpoons \mathrm{IO}_{4}^{-}+2 \mathrm{H}_{2} \mathrm{O}
\end{aligned}
$$

$$
\begin{aligned}
& \mathrm{H}_{4} \mathrm{IO}_{6}{ }^{-} \rightleftharpoons \mathrm{H}_{3} \mathrm{IO}_{6}^{-2}+\mathrm{H}^{+} \\
& \mathrm{H}_{3} \mathrm{IO}_{6}{ }^{2-} \rightleftharpoons \mathrm{H}_{2} \mathrm{IO}_{6}^{-3}+\mathrm{H}+
\end{aligned}
$$

The mono anion $\mathrm{H}_{4} \mathrm{IO}_{6}{ }^{-}$is largly dehydrated to tetrahedral $\mathrm{IO}_{4}^{-}$. The activity of periodate ion as an oxidizing agent varies greatly as the function of $\mathrm{pH}$ and this is expected because of accompanying change in the degree of ionization of periodate ${ }^{13,14}$. Thus in acidic solution $\mathrm{H}_{5} \mathrm{IO}_{6}, \mathrm{H}_{4} \mathrm{IO}_{6}^{-}, \mathrm{IO}_{4}^{-}, \mathrm{H}_{3} \mathrm{IO}_{6}^{-2}$ and $\mathrm{H}_{2} \mathrm{IO}_{6}^{-3}$ can act as oxidizing species. Of these species, possibility of $\mathrm{H}_{4} \mathrm{IO}_{6}{ }^{-}, \mathrm{H}_{3} \mathrm{IO}_{6}{ }^{2-}$ and $\mathrm{H}_{2} \mathrm{IO}_{6}{ }^{3-}$ as oxidizing species is ruled out as these will require negative effect of $\left[\mathrm{H}^{+}\right]$contrary to the observed positive effect of $\left[\mathrm{H}^{+}\right]$on the rate. $\mathrm{H}_{5} \mathrm{IO}_{6}$ will also require decreasing effect of $\left[\mathrm{H}^{+}\right]$and hence it is also ruled out as oxidizing species. Now the only choice left is $\mathrm{IO}_{4}^{-}$which when taken as oxidizing species explains all the observed kinetic results. Since order in [periodate] is zero which requires its involvement in fast reaction after slow and rate determining step, hence it matters little which one of the aforesaid species is involved in fast step.

It has been reported ${ }^{15}$ that in dilute $\mathrm{HCl}$ solution ruthenium(III) chloride exists as $\left[\mathrm{RuCl}_{6}\right]^{3-}$, which is involved in the following equilibrium.

$$
\left[\mathrm{RuCl}_{6}\right]^{3-}+\mathrm{H}_{2} \mathrm{O} \rightleftharpoons\left[\mathrm{RuCl}_{5}\left(\mathrm{H}_{2} \mathrm{O}\right)\right]^{2-}+\mathrm{Cl}^{-}
$$

Thus either of $\left[\mathrm{RuCl}_{6}\right]^{3-}$ or $\left[\mathrm{RuCl}_{5}\left(\mathrm{H}_{2} \mathrm{O}\right)\right]^{2-}$ may be effective catalytic species. It has also been reported that in acidic medium periodate ion rapidly converts ${ }^{16} \mathrm{Ru}(\mathrm{III})$ to $\mathrm{Ru}(\mathrm{VIII})$ according to the reaction given below which is faster than periodate oxidations.

\begin{tabular}{|c|c|c|c|c|}
\hline \multirow{2}{*}{ Temperature $\left({ }^{\circ} \mathrm{C}\right)$} & \multirow{2}{*}[\mathrm{HClO}_{4}]{$\times 10^{2}\left(\mathrm{~mol} \mathrm{dm}^{-3}\right)$} & \multirow{2}{*}[\mathrm{KCl}]{$\times 10^{3}\left(\mathrm{~mol} \mathrm{dm}^{-3}\right)$} & \multicolumn{2}{|c|}{$[-\mathrm{dc} / \mathrm{dt}] \times 10^{7}\left(\mathrm{~mol} \mathrm{dm}^{-3} \mathrm{~s}^{-1}\right)$} \\
\hline & & & MG & DAA \\
\hline 25 & 1.00 & 1.00 & 0.40 & $1.02^{\mathrm{a}}$ \\
\hline 30 & 1.00 & 1.00 & 0.64 & $1.70^{\mathrm{a}}$ \\
\hline 35 & 1.00 & 1.00 & 1.08 & $2.36^{\mathrm{a}}$ \\
\hline 40 & 1.00 & 1.00 & 1.38 & $3.96^{\mathrm{a}}$ \\
\hline 30 & 0.50 & 1.00 & 0.48 & 0.76 \\
\hline 30 & 1.00 & 1.00 & 0.64 & 1.08 \\
\hline 30 & 1.50 & 1.00 & 0.84 & 1.36 \\
\hline 30 & 2.00 & 1.00 & 1.04 & 1.70 \\
\hline 30 & 2.50 & 1.00 & 1.26 & 1.84 \\
\hline 30 & 3.00 & 1.00 & 1.48 & 2.16 \\
\hline 30 & 1.00 & 0.50 & 0.64 & $1.72^{\mathrm{a}}$ \\
\hline 30 & 1.00 & 1.00 & 0.67 & $1.66^{\mathrm{a}}$ \\
\hline 30 & 1.00 & 1.50 & 0.62 & $1.70^{\mathrm{a}}$ \\
\hline 30 & 1.00 & 2.00 & 0.68 & $1.68^{\mathrm{a}}$ \\
\hline 30 & 1.00 & 2.50 & 0.65 & $1.72^{\mathrm{a}}$ \\
\hline 30 & 1.00 & 3.00 & 0.66 & $1.74^{\mathrm{a}}$ \\
\hline
\end{tabular}

$$
2 \mathrm{Ru}(\mathrm{III})+5 \mathrm{IO}_{4}^{-}+10 \mathrm{H}^{+} \rightarrow 2 \mathrm{Ru}(\mathrm{VIII})+5 \mathrm{IO}_{3}{ }^{-}+5 \mathrm{H}_{2} \mathrm{O}(\mathrm{f})
$$

TABLE-2

EFFECT OF VARIATION OF $\left[\mathrm{HClO}_{4}\right]$, TEMPERATURE AND ADDITION OF KCl ON THE RATE OF OXIDATION OF MG AND DAA AT

\begin{tabular}{|c|c|c|c|c|c|c|}
\hline Substrate & $\mathrm{k}_{\mathrm{r}}\left(\mathrm{mol}^{-2} \mathrm{~L}^{2} \mathrm{~s}^{-1}\right)$ & $\log A$ & $\mathrm{E}_{\mathrm{a}}(\mathrm{kcal} / \mathrm{mol})$ & $\Delta \mathrm{H}^{\#}(\mathrm{kcal} / \mathrm{mol})$ & $\Delta S^{\#}$ eu & $\Delta \mathrm{G}^{\#}(\mathrm{kcal} / \mathrm{mol})$ \\
\hline MG & 6.03 & 12.78 & 16.65 & 16.04 & -2.07 & 16.67 \\
\hline DAA & 19.95 & 12.59 & 15.74 & 15.13 & -2.94 & 16.02 \\
\hline
\end{tabular}
$30^{\circ} \mathrm{C}$ (UNLESS OTHERWISE STATED) $\left[\mathrm{NaIO}_{4}\right]=1 \times 10^{-3} \mathrm{~mol} \mathrm{dm}^{-3},[$ Substrate $]=2 \times 10^{-2} \mathrm{~mol} \mathrm{dm}^{-3}, \&[\mathrm{Ru}(\mathrm{III})]=9.60 \times 10^{-6} \mathrm{~mol} \mathrm{dm}^{-3}$

TABLE-3

ACTIVATION PARAMETERS IN Ru(III) CATALYSED OXIDATION OF METHYL GLYCOL (MG) AND DIACETONE ALCOHOL (DAA) BY ACIDIC SOLUTION OF SODIUM METAPERIODATE AT $30^{\circ} \mathrm{C}$ 
$\mathrm{Ru}(\mathrm{VIII})$ is reported ${ }^{17}$ to be present in the form of $\mathrm{H}_{2} \mathrm{RuO}_{5}$ or $\mathrm{RuO}_{3}(\mathrm{OH})_{2}$ in the acidic medium. Hence, here $\mathrm{H}_{2} \mathrm{RuO}_{5}$ is assumed to be effective catalytic species in the present investigation. Thus catalytic action of $\mathrm{Ru}(\mathrm{III})$ occurs through $\mathrm{Ru}(\mathrm{VIII})$ centre.

On the basis of $\mathrm{IO}_{4}{ }^{-}$and $\mathrm{H}_{2} \mathrm{RuO}_{5}$ as oxidizing and catalytic species, respectively and considering other kinetic results and stoichiometric data, the following reaction mechanism is suggested for oxidation of MG and DAA as both exhibit common kinetic results. Here, S stands for substrates (MG and/or DAA).

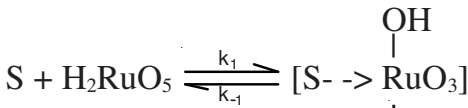

$$
\begin{aligned}
& \left(\mathrm{C}_{1}\right) \\
& \mathrm{C}_{1}+\mathrm{H}^{+} \underset{\mathrm{k}_{-2}}{\stackrel{\mathrm{k}_{2}}{\rightleftharpoons}}\left[\mathrm{C}_{2}\right]^{+} \\
& {\left[\mathrm{C}_{2}\right]^{+} \underset{\text { slow }}{\stackrel{\mathrm{k}_{\mathrm{d}}}{\longrightarrow}}\left[\mathrm{OH}-\mathrm{RuO}_{3}(\mathrm{H})\right]+\mathrm{S}^{+}+\mathrm{H}_{2} \mathrm{O}} \\
& {\left[\mathrm{OH}-\mathrm{RuO}_{3}(\mathrm{H})\right]+\mathrm{IO}_{4}^{-} \longrightarrow \mathrm{H}_{2} \mathrm{RuO}_{5}+\mathrm{IO}_{3}{ }^{-}} \\
& \mathrm{S}^{+}+\mathrm{IO}_{4}{ }^{-} \longrightarrow \mathrm{RCOOH}+\mathrm{IO}_{3}{ }^{-}+\mathrm{H}^{+}
\end{aligned}
$$

where $\mathrm{R}$ is $\mathrm{CH}_{3} \mathrm{CHOH}$ - group in $\mathrm{MG}$ and in step $\mathrm{S}^{+}$stands for $\mathrm{CH}_{3} \mathrm{CHOH}$ carbonium ion from $\mathrm{MG}$. I $\mathrm{CHOH}$

In case of DAA,

$$
\mathrm{S}^{+} \text {stands for } \mathrm{CH}_{3}-\underset{\oplus}{\mathrm{C}(\mathrm{OH})-\mathrm{CH}_{2}-} \stackrel{\text { II }}{\mathrm{C}}-\mathrm{CH}_{2} \text { which is oxidizing }
$$

in step

$$
\mathrm{S}^{+}+3 \mathrm{IO}_{4}^{-} \longrightarrow \begin{gathered}
\mathrm{CH}_{3} \mathrm{COCH}_{3}+\mathrm{CH}_{3} \mathrm{COOH}+ \\
3 \mathrm{IO}_{3}^{-}+\mathrm{H}^{+}+\mathrm{CO}_{2}
\end{gathered}
$$
consumed where $n=2$ in $M G$ and 4 in DAA oxidation.

Considering aforesaid reaction steps and stoichiometry of the reactions, rate of reactions can be written in term of rate of loss of $\left[\mathrm{IO}_{4}^{-}\right]$as eqn (1) -

$$
-\frac{\mathrm{d}\left[\mathrm{IO}_{4}^{-}\right]}{\mathrm{dt}}=\mathrm{nk}_{\mathrm{d}}\left[\mathrm{C}_{2}\right]^{+}
$$

By applying the law of equilibrium in step (II) -

$$
\left[\mathrm{C}_{2}\right]=\mathrm{K}_{2}\left[\mathrm{C}_{1}\right][\mathrm{H}]^{+}
$$

On applying steady state to $\left[\mathrm{C}_{1}\right]$ and considering steps (i)

$$
\left[\mathrm{C}_{2}\right]=\frac{\mathrm{k}_{1}[\mathrm{~S}]\left[\mathrm{H}_{2} \mathrm{RuO}_{5}\right]}{\mathrm{k}_{-1}+\mathrm{k}_{2}[\mathrm{H}]^{+}}
$$

On substituting the value of $\left[\mathrm{C}_{1}\right]$ from eqn (3) in eqn (2)

$$
\left[\mathrm{C}_{2}\right]=\frac{\mathrm{k}_{1} \mathrm{~K}_{2}[\mathrm{~S}]\left[\mathrm{H}_{2} \mathrm{RuO}_{5}\right][\mathrm{H}]^{+}}{\mathrm{k}_{-1}+\mathrm{k}_{2}[\mathrm{H}]^{+}}
$$

where $\mathrm{K}_{2}=\mathrm{k}_{2} / \mathrm{k}_{-2}$

By considering eqn (1) and (4) together

$$
-\frac{\mathrm{d}\left[\mathrm{IO}_{4}^{-}\right]}{\mathrm{dt}}=\frac{\mathrm{nk}_{\mathrm{d}} \mathrm{k}_{1} \mathrm{~K}_{2}[\mathrm{~S}][\mathrm{H}]^{+}\left[\mathrm{H}_{2} \mathrm{RuO}_{5}\right]}{\mathrm{k}_{-1}+\mathrm{k}_{2}[\mathrm{H}]^{+}}
$$

The rate law (5) satisfies and explains all the observed kinetic results. It explains positive effect of $[\mathrm{H}]^{+}$and zero effect of $\left[\mathrm{Cl}^{-}\right]$on the rate of the reaction.

\section{REFERENCES}

1. C.V. Hiremath, T.S. Kiran and S.T. Nandibewoor, J. Mol. Catal. Chem., 248, 163 (2006).

2. B. Singh, A. Ratan, V. Prakash and D.M. Kesarwani, Oxid. Commun., 19, 552 (1996).

3. D.L. Kamble and S.T. Nandibewoor, J. Phys. Org. Chem., 11, 171 (1998).

4. M.M. Taqui Khan and R.S. Shukla, J. Mol. Catal., 34, 19 (1986).

5. A.K. Singh, A. Singh, R. Gupta, M. Saxena and B. Singh, Transition Met. Chem., 17, 413 (1992).

6. AK. Singh, R. Negi, B. Jain, Y. Katre, S.P. Singh and V.K. Sharma, Catal. Lett., 132, 285 (2009).

7. G.A. Hiremath, P.L. Timmanagoudar, R.B. Chougale and S.T. Nandibewoor, J. Indian Chem. Soc., 75, 363 (1988).

8. Ashish, S.P. Singh, A.K. Singh and B. Singh, J. Mol. Catal. Chem., 266, 226 (2007).

9. C.A. Bunton, in ed.: K.B. Wiberg, Oxidation in Organic Chemistry, Part A, Academic Press, New York, p. 368 (1965).

10. S.P. Srivastava, G. Bhattacharjee and P. Malik, Indian J. Chem., 25A, 48 (1986).

11. A.K. Singh and A.K. Sisodia, S. Saxena and M. Saxena, Indian J. Chem., 26A, 600 (1987).

12. F. Feigl, Spot Tests in Organic Analysis, Elsevier, New York, edn 7 (1975).

13. C.E. Crouthamel, H.V. Meek, D.S. Martin and C.V. Banks, J. Am. Chem. Soc., 71, 3031 (1949).

14. C.E. Grouthamel, A.M. Hayes and D.S. Martin, J. Am. Chem. Soc., 73, 82 (1951).

15. C. Waquar, J.P. Sharma and B. Singh, Oxid. Commun., 12, 115 1989).

16. T.D. Avtokratova, Analytical Chemistry of Ruthenium, Humphrey Science Publication, London (1969).

17. F.S. Martin, J. Chem. Soc., 2564 (1954). and (ii), 